\title{
Teaching the TV Teacher
}

\author{
EDWARd STAShefF
}

\author{
To quote Rudyard Kipling: \\ There are six-and-twenty ways \\ Of constructing tribal lays, \\ And every single one of them is right.
}

The same is true of teaching the television teacher, whether Studio Teacher or TV Classroom Teacher. The type of preparation given to a neophyte studio teacher, for example, still depends on such obvious factors as the availability of camera rehearsal time and of such supporting facilities as films and slides, art work, and models. Perhaps even more important are the personality of the teacher himself, the nature of the subject to be taught, and the grade level at which it is aimed.

The education of the Television Classroom Teacher (and the use of capitals is deliberate) is equally important. It is regrettable that relatively few schools of education or departments of education make a full course in TV utilization available, not to say compulsory. Our friends in the audiovisual education courses have helped increasingly in recent years, but a three-hour course in Methods and Materials of Audiovisual Education can give just so many hours to procedures for using $\mathrm{TV}$ in the classroom.

To begin with, those who are to train the studio teacher should have some voice in his selection. My recent experience with the Instructional Television Trust of Israel, in helping

Edward Stasheff is professor of speech (radio and television) at the University of Michigan and has conducted many workshops for television teachers. He has recently returned from a year in Israel as Director of Production for its first TV station. 
to set up that nation's first TV facility, is a case in point. Two months before my work there as Director of Production began, I was sent to Israel to assist the Director of Education in selecting the teachers who would face the cameras a year later. This may seem to be an ideal situation, but in practice it turned out that the two weeks allotted for selecting trainees was not enough:

What were the criteria for selection? Certainly, knowledge of the subject to be taught and competence in its presentation came first. Candidates for TV teaching should already have been screened for their teaching skill, leaving the television man to look for the following:

flexibility and potential for growth

pleasing appearance on camera-which does not mean the traditional Hollywood photogenic quality

that elusive quality called "personality" good speech, including clarity of diction imagination and, if possible, a feeling for visual presentation humor, a purely personal preference which may not be ac. ceptable to all school systems

Once the teachers have been chosen for training, how do we begin? It may be helpful to divide this discussion into the psychological, physical, and technical factors involved in the training period.

\section{Psychological Factors}

Among the psychological factors, perhaps the most important is the problem of getting the new teacher to feel at ease in the studio. One never mentions the words "stage fright" or "camera fright," to be sure, but they do exist. While the real remedy is experience, such experience does not take hold until about the third week of broadcasting; something must be done about the first two.

One helpful procedure in putting the trainee at ease is to adapt to instructional television the "buddy-teacher system," in which an experienced teacher takes under her wing a neophyte. The same approach will operate in a studio, if a teacher with some years of broadcasting experience is asked to work with a beginner. Another good rule is to try to team a new director with an experienced teacher and an ex- 
perienced director with a new teacher. Although this is not always possible, it is sometimes not done when it could be done.

It is also helpful to conduct a preliminary training seminar for several weeks, preferably at the end of June if the new teacher is to begin broadcasting in September. The seminar should be held before serious work starts on the preparation of such things as scripts, teachers' guides, manuals, and curriculum resource outlines. Some studios and school systems open such a seminar or training course by screening "The Studio Teacher," a training kinescope designed for this purpose and available at a very modest rental from the Great Plains Instructional TV Library, at the University of Nebraska.

Script preparation is another very important step in the training process. Few instructional television setups in the United States can afford to assign editors to help the teacher with approach, structure, and final polishing of the script. In Japan and occasionally in some other countries this is done as a matter of course, but in the United States a supervisor, producer, or director usually has this responsibility.

The more skillfully a TV script has been prepared, the less time needed to shape it to the needs of students and the resources of the studio. Let the new teacher browse through old scripts, preferably in the subject he is to teach but not necessarily at the same grade level.

\section{Physical Problems}

The physical problems involved are those which primarily affect the teacher and only secondarily affect his relationship with electronic equipment. These concern "handling"teaching the teacher how to handle himself before camera, how to handle props or objects, how to handle or draw on graphics, how to handle the cord of a chest microphone. Examples of "handling" include techniques of rising and walking, of standing at the chalkboard or magnet board, and of pointing, manipulating, or writing.

The need for moderate speed in moving objects and for accuracy in placing them is obvious to an experienced teacher, but may be difficult for a neophyte to realize. The need for proper handling of a chest microphone at a chalk- 
board, for example, will be clear to the beginning teacher once he has reached up high on the board while talking, thus changing sound level and presence, or when he has spoken while leaning close in to the hard-surfaced board, thus creating a narrow but effective echo chamber.

Perhaps the most important problem is persuading the teacher to make eye contact with the "taking lens," the one which is picking up the teacher's image at a given moment. I have found it helpful to persuade teachers not to look at the taking lens but through it-right into the eye of each student in every classroom which is tuned in. One might even suggest that a miniature student is curled up inside the camera, and that the teacher is to speak to him.

Sometimes in the early stages, a sympathetic floor manager stands close to the camera and reacts to everything the teacher says and does. This helps penetrate the barrier between new teachers addressing an invisible class and an alltoo-visible four-eyed monster called a TV camera.

\section{Technical Training}

The technical part of the teacher's education runs the gamut from dress (neither black nor white, no flashing tieclips or earrings, etc.) to cueing the director and choosing "props," the objects shown on camera. One rule of thumb about cues for introducing a film segment: even if the whole program is to be given ex tempora from a prepared outline (a process many producers prefer to the memorized lesson), the "roll cue," or exact words which precede the film, must be given verbatim.

As for props, they should be checked on camera or at least shown to the director well before air time. A rough rule to follow in choosing props: "Don't use anything which is smaller than your fist or bigger than the door leading into the studio." Obviously, such matters as color value, contrast, and suitability to background will be left to the discretion of the director until the teacher becomes experienced.

Some experienced teachers learn too much about production. They not only learn enough about the visual tools of TV to plan for them in script preparation, but they begin to advise the director on anything from lighting to camera angles. "A little knowledge is a dangerous thing. ..." 
The best television lessons come when the teamwork between teacher and director leads not only to a meeting of minds but almost to a reading of minds. Of course, the director will occasionally make a suggestion about lesson content or structure, and the teacher by the end of his first year in the studio will incorporate production techniques in the scripts he prepares. But the basic rule of "each to his own" still holds, as does the remark: "Experience teaches you when and how the rules should be broken." 